\title{
La lectura de novelas como instrumento para interpretar la historia. Los casos de Galdós y Coloma'
}

\author{
The Case of Luis Coloma \\ RICARDO SERNA GALINDO \\ Universidad de Jaén \\ España \\ ricardoserna54@gmail.com
}

Reading Novels as a Tool for Interpreting History.

(Recibido: : o8-II-20I6; aceptado: $07-03-20 I 7)$

Resumen. El presente artículo acomete el proyecto de dejar constancia de la importancia cultural que tiene la lectura de obras literarias. Lo literario se vincula a nuestras vidas de manera indeleble y merece la pena reflexionar sobre ello. Se reivindica la figura del escritor como elemento clave del proceso creativo, y se contempla el género novelesco a manera de fuente valiosa para la interpretación de la historia. En este sentido se estima la obra de Benito Pérez Galdós, al que algunos historiadores avezados se aproximan para confeccionar o completar su visión de hechos históricos concretos o de épocas y ambientes determinados. En el caso de Galdós, apreciamos nexos entre la literatura y la historia española del siglo XIX. Algo similar — salvando las distancias- ocurre con la novela Pequeñeces (1890), del escritor Luis Coloma, que nos ofrece una visión certera del tejido aristocrático en la convulsa España del Sexenio revolucionario (I868-1874).

Palabras clave: escritura creativa; novela; fuentes de información; Benito Pérez Galdós; Luis Coloma.
Abstract. This article undertakes the project of recording the cultural importance of reading literary works. Literature links to our lives in indelible ways and it is worth reflecting on this. The figure of the writer as a key element of the creative process is applied, and the novel is contemplated as a valuable source for the interpretation of history. That is how the novels by Benito Pérez Galdós are considered. Some experienced historians approach him to make or complete their vision of specific historical events or periods and certain environments. In the case of Galdós, we observe links between Spanish literature and history of the 19th century. Despite some differences, there is a similar process with the Pequeñeces (1890), a novel by the writer Luis Coloma, which provides us with an accurate view of the aristocratic network in the tumultuous Spain of the Revolutionary Six Years Period (1868-1874).

Keywords: creative writing; novel; information sources; history; Benito Pérez Galdós; Luis Coloma.

\footnotetext{
${ }^{\text {I }}$ Para citar este artículo:: Serna Galindo, Ricardo (2OI7). La lectura de novelas como instrumento para interpretar la historia. Los casos de Galdós y Coloma. Alabe 16. [www.revistaalabe.com]

DOI: Io.I5645/Älabe20I7.I6.5
} 


\section{A modo de introducción. Historiadores y literatos}

Frente al documento frío que puede utilizar un historiador en el desarrollo de su trabajo, el texto literario nos ofrece en ocasiones otra visión de la realidad, perspectiva que no es mejor ni peor, sino distinta en su forma y con otras leyes interpretativas. La historia aparece en ciertas novelas porque refleja de alguna forma la experiencia del escritor, que se convierte a veces en testigo de su época.

En este proceso de análisis, es importante que el historiador conozca lo más posible al literato y su obra, de tal modo que sea capaz de interpretar con la precisión conveniente los datos vertidos en textos valiosos para el quehacer histórico. La esencia creativa del literato está inmersa en el factor imaginativo, porque un escritor es alguien que inventa aun sirviéndose para ello de la experiencia y los hechos que le rodean. El historiador ha de conocer la biografía y trayectoria del literato, su estilo y maneras de expresión y su capacidad para incidir de un modo concreto en determinados círculos o asuntos fundamentales. Todo esto es preciso si se pretende tener la capacidad de rescatar de la narrativa los datos que son vitales a la hora de generar o reinterpretar la historia.

Nadie duda de la importancia de Galdós como literato propenso a contar y dejar testimonio de la historia a través de sus textos creativos, y es por esta razón por la que desarrollaremos una alusión en torno al escritor canario y su manera peculiar de transmitir el suceso histórico. Aludiremos igualmente al libro de Miralles La segunda serie de los Episodios nacionales de Benito Pérez Galdós. De la historia a la novela, un ensayo del año $20{ }_{5}$ en el que se aborda la figura de Galdós y parte de sus Episodios desde una perspectiva novedosa y digna de mención, en el filo cortante y delicado que separa lo creativo de lo histórico o viceversa.

Es evidente que la novela puede ser una fuente de información para el historiador. Por eso se abordan también las complejidades de un género apto para la narración de experiencias, atalaya desde la que ciertos autores han sido capaces de construir textos en los que hay un volcado más o menos artificioso de vida propia y de testimonio (Lejeune, I994). En la novela es posible hallar materia prima de deducción histórica con valor para llevar a cabo una reinterpretación de épocas, periodos o momentos puntuales. De ahí que este género resulte valioso como fuente para el historiador.

No obstante, el profesional de la historia sondea en la literatura el testimonio vivo de una sociedad, e incluso la manifestación de mentalidades que el escritor refleja en su objeto de creación y frente a las que él mismo toma partido por medio de sus personajes. Inevitablemente, se suele acudir a un ejemplo obvio: Los Episodios Nacionales de Pérez Galdós. «Según Chartier, los historiadores, en la actualidad, saben que el conocimiento que producen no es más que una de las modalidades de la relación que las sociedades mantienen con el pasado» (Vila Vilar, 20o9). En cualquier caso, la interpretación histórica, y su plasmación en un texto, es solo una visión subjetiva más de una verdad precisa que hallamos varada en el pasado a merced de los diversos analistas. Cada interpretación 
tiene sus porqués y responde a una visión concreta del ayer, bien se haga recurriendo a la literatura o sin tenerla en cuenta.

No se puede afirmar que los historiadores consideran en general la obra literaria como algo alejado de sus fuentes, pero es verdad que en ocasiones suelen verla como pista histórica de menor entidad. El debate sobre la relación entre literatura e historia tiene un final poco claro la mayoría de las veces. Por un lado se acusa a la obra literaria de falta de hondura histórica, pues proviene en definitiva de un hecho imaginativo y artístico, y se culpa a la historia de contextualizar los textos literarios hasta reducirlos a mera anécdota. De otro lado, a muchos historiadores les parece dificultoso meterse en interpretaciones de fondo literario, ya que ignoran de qué forma deben valorar los datos aportados por los escritores, y optan por eludir la literatura en sus trabajos de investigación. La literatura se puede y debe examinar como una vía de diálogo interdisciplinar, viéndola como fuente y objeto de la historia. La narrativa de creación nos transmite sin duda su verdad histórica, y el profesional ha de traducir al lenguaje historiográfico lo que los escritores describen por medio de su propio código.

La académica Carmen Iglesias ingresó en la Real Academia Española con un discurso que tituló «De historia y de Literatura como elementos de ficción», donde viene a definir con originalidad y lucidez los limes naturales y apreciables entre ambos campos. Señala que si la historia se ocupa del pasado desde el presente a fin de intuir un futuro, la literatura otea el futuro a través de ese presente. Conviene delimitar el tiempo histórico y el tiempo literario a la hora de brindar interpretaciones, que siempre son subjetivas por definición de su esencia.

Los que dedican su tiempo y trabajo a las ciencias sociales, hace tiempo que son conscientes de que la tendencia actual radica en el concepto de interdisciplinaridad, y por ello se regresa poco a poco al espíritu académico de siglos atrás. Los historiadores se sienten de algún modo impelidos a reinventar fuentes nuevas y renovados métodos de análisis para el logro de resultados de más amplio espectro. De ahí que muchos incorporen a sus fuentes ese mundo de gentes sin nombre que configuran la otra historia, y que son a la postre personajes que imprimen a la investigación historiográfica la entraña y el alma de lo humano.

Son muchos los autores literarios que han remarcado la importancia de la dimensión literaria en la disciplina histórica, entre ellos Alejo Carpentier, quien escribió al respecto de la interrelación existente entre la novela y la historia incidiendo en el hecho de que la novela tiene la virtud de saltarse constantemente el plano de la invención meramente estética para recalar en la dársena de la indagación histórica, superando incluso la conciencia de su propio autor en este aspecto de su idiosincrasia. Y efectivamente, si repasamos los grandes nombres de la literatura universal, se observa que sucede esto mismo con numerosas obras de Cervantes, Shakespeare, Balzac, Galdós, Baroja y otros más cercanos a nuestra contemporaneidad. 


\section{La trascendencia del hecho literario}

La literatura es el arte que emplea la palabra en su código escrito como principal instrumento vehicular. Y la creación literaria es una de las más altas consecuciones de las sociedades libres y avanzadas. Lo literario forma parte de la vida, de la lectura y la experiencia; es parte del ser humano, de su tradición y aprendizaje. Sirve la literatura, aun inconscientemente, como práctica asimilada y aprehendida que ayuda al ser social a desenvolverse en sus conversaciones y contactos, incluso en las más variadas acciones relacionadas o no con actividades del intelecto (Díaz-Plaja, I969). Y rinde también para ver la historia a su través con filtros sutiles que ayudan a interpretarla luego con las proyecciones cálidas que pocas veces ofrece un documento.

La literatura es capaz de mostrarnos, o cuando menos hacernos intuir, facetas biográficas recónditas de ciertos personajes que a lo peor el dato documental no es capaz de elevar a rango de cuasi certidumbre, como sucede con algunos protagonistas que han forjado determinados episodios importantes de la historia de sus naciones y se han convertido en auténticos mitos, caso del gaditano Fermín Galán o del filipino José Rizal. A través de sus obras literarias, o de escritos ajenos que versan sobre sus vidas o trayectorias, nos resulta posible obtener una visión más objetiva, original y cercana del personaje. La historia de la literatura se aproxima en ciertos casos a la historia de los hechos para completarla o auxiliarla (Mainer Baqué, 2015: 37-64).

La literatura como fenómeno es consustancial con la formación del sujeto actual, con su idea de la vida, de los sentimientos, de la razón. Y el factor imaginativo ha sido muy ensalzado por los maestros de la psicología como un elemento de apoyo en el desarrollo del aspecto simbólico individual. Es innegable que algunos escritores desarrollan más que otros el lado alegórico en sus escritos, caso de Ítalo Calvino por ejemplo, pero la mayoría presentan una clara tendencia hacia la representación figurada a través del objeto descrito (Fucini, 2005: 227-233).

De lo dicho se colige que la literatura es una de las disciplinas más interesantes y formativas de la educación y de la vida, tanto del individuo como de la sociedad en su conjunto. En su obra Memorias, Pío Baroja escribe que «la historia es una rama de la literatura» (Baroja y Nessi, I982: 276). Sin sacar la frase de su entorno contextual, hay que recordar la sentencia barojiana para subrayar que lo literario tiene importancia capital en cualquier actividad humana, incluso en las ocasiones en que pueda no parecerlo (González Martín, r996: 789-8I4). A veces no se presta la debida atención a un fenómeno al que erróneamente se etiqueta hijo único de la fantasía o -lo que es todavía peor- renuevo bastardo de otras disciplinas presuntamente más exactas. La literatura creativa llega a ser tan importante a veces, que el historiador ha de navegar en sus aguas para entresacar verdades que subyacen entre líneas y que, como en el caso de la obra de Galdós, resultan de interés para el investigador de la época (Mainer Baqué, r998: 83-98; Sánchez García, 2007: 28I-290). Cuando hay escasez de fuentes netamente históricas, o cuando estas dejan que desear, es indispensable acudir a la literatura creativa de los autores 
contemporáneos al hecho investigado (Almela Boix, 2006: 97-I42). La novelística, las memorias, la correspondencia entre escritores, las cartas personales, los ensayos, los relatos de costumbres o los comentarios y anotaciones de ciertas obras literarias, constituyen un campo de actuación del que no debe ser ajeno el historiador perspicaz (Abellán, ı971; Pérez Galdós, 20i6).

Lo literario no tiene por qué pertenecer al ámbito de lo irreal, de lo ensoñado; y aun perteneciendo a él en según qué casos, enseña y hace pensar. De manera análoga lo entendía el francmasón José Martí, que siempre tuvo gran admiración por novelistas en cuyas obras se reflejase, con la matización propia y deseada de la obra literaria, la historia de su patria o comunidad (Blanco Rodríguez, I996: 2II-223; Sánchez Gálvez, 2OO7).

El carácter de la literatura es a menudo testimonial, aunque se aborde bajo el imperio del estilo y en el marco de un determinado género o subgénero. El historiador ha de tener la necesaria versucia para valorar de manera positiva la parcela literaria, pues dicha veta puede constituir, en determinados momentos de su labor investigadora, un filón inapreciable de indicios, datos o confirmaciones de sus iniciales presupuestos (Fernández Rodríguez, 2OOI: 3OI-352).

\section{Lo que el historiador ha de saber del literato}

Es muy útil que el historiador, el investigador, conozca la idiosincrasia del literato al que acude, aunque solo sea en términos generales. Si al menos conoce la condición de los creadores, podrá entender mejor las pistas históricas que estos vierten en sus obras narrativas respectivas (White, 2003).

La utilización de la herramienta imaginativa por parte del escritor es importante, de tal modo que lo creativo no debe considerarse como tal si hay ausencia o inhibición del factor imaginativo, componente esencial en literatura. Así se pone en valor la idea de que un literato es el escritor que inventa aun valiéndose para ello de la vida misma. Esto no es óbice para que a otros intelectuales podamos tenerlos en cuenta a veces en su rol de ocasionales literatos. Como deja constancia el filólogo e historiador francés Renan, la imaginación es la facultad que dibuja, modela y da valor a nuestras ideas; es la intermediaria indispensable entre el pensamiento, el deseo y la realización. Por tanto, su papel es decisivo (Renan, I972; White, I992).

El historiador indaga y desvela el pasado a través de su propia subjetividad, dibujando un ayer que mantiene su persistencia en el presente; el escritor lo narra o lo cuenta a su modo (Megill, ı993: 7I-96; Moradiellos García, 2004). Ambos métodos de actuación son claramente distintos. Escribe Pedro Salinas: «Empezamos a sospechar una verdad: que el escritor es, entre los tipos humanos, el más raro y singular, y su situación en el mundo peregrina y aventurada como ninguna» (Salinas Serrano, I970: 217). Para perpetuar en el tiempo una sociedad moderna, abierta y comprensiva, nos parece indispensable la fortaleza y el buen estado de salud de la cultura. Y un actor fundamental en 
el círculo de lo cultural es el creador, el escritor, ese personaje singular al que se refiere Salinas en su ensayo.

La figura del escritor suele ser la menos comprendida. Hay quien se pregunta a qué obedece esto, y hasta qué punto es sacrificado el oficio de escritor. En términos generales, suele ser un tipo literalmente escandaloso e incomprendido:

Irremediablemente es forzado a explicar su propia intimidad, aun cuando crea tantas veces escamotearla con alegorías más o menos transparentes. Los episodios de su peripecia interior quedan así, inermes, a merced de la plazuela, sin que el escritor pueda quejarse de ello. No hay literatura sin proyección social. Escribir es catapultar nuestros sentimientos hacia objetivos multitudinarios, en los que jamás podremos conocer la dimensión ni la profundidad del impacto (Díaz-Plaja, 1969: 2I-22).

Ese impacto, salvo excepciones marcadas por la mercadotecnia o la casualidad, no suele ser extenso ni excesivo. Los literatos no escriben para multitudes, sino para ese lector anónimo que lee libros a ratos, antes de acostarse quizá, o en la madrugada al lado de su chimenea. El escritor imagina a ese lector de mil maneras; luego se pelea por él mejorando la forma o los argumentos de su próximo libro.

En literatura creativa, nada ha de extrañar. Un escritor no es sino un ser explícito que se desangra, pluma en mano, durante años. El caso de Unamuno, por ejemplo, es significativo. Lo que el lector valora en un escritor es el rasgo personal, el detalle diferenciador e íntimo que lo separa de otros seres vulgares (Díaz Freire, 2OI5: 2I-44). «Lo que hace de Unamuno un escritor formidable es la impresión que nos produce de ser un pelícano monstruoso que se abre el pecho a picotazos. Lo demás no tiene importancia» (Díaz-Plaja, ı969: 23).

En cada época, el escritor se vuelca de una forma distinta en el seno de su obra. Cada tiempo crea sus propios topes referenciales de lo íntimo. En el siglo XVIII, Jovellanos se disculpaba explícitamente con los lectores por escribir alguna pequeña frase de tipo sentimental. En el Neoclasicismo, la intimidad del autor no pasaba de ser una provocación imperdonable. Con la llegada del Romanticismo, en cambio, se hizo del yo un auténtico protagonista de la creación. Y desde entonces acá, la moda se tradujo en costumbre. Es obvio que el autor está presente en su discurso, incluso aun sin pretenderlo. Por eso es tan importante que el investigador de la historia cuide de ahondar en la figura del literato al buscar vetas de historia en sus relatos y novelas (López Romero, 2OOI).

Gómez de la Serna, un adelantado a su tiempo que supo pensar como un genio y escribir luego en consecuencia, no dejó de tratar este asunto, y quiso dejarnos su definición de la figura del escritor. «Para ser escritor - afirma- hay que saber escribir y, además, estar un poco moribundo» (Gómez de la Serna, I970: 65). 
El mundo moderno pretende fagocitar al escritor, sobre todo al que no se adapta bien a las técnicas y comportamientos últimos. Porque el literato, por su rareza, se convierte para la estirpe de la modernidad simplona en bocado apetecible. El creador literario -debe saberlo el investigador de la historia- es hacedor de mucha muerte propia en sus personajes, el escritor se inmola a diario sin esperar excesiva recompensa. En las ansias y expectativas del escritor radica el resultado de su paternidad y originalidad.

Si hago hincapié en el nacimiento del acto literario, en la producción de la escritura -escribe Nadeau-, es porque contemplo en todo escritor a un individuo que rechaza primero el lenguaje común, ni que decir tiene, pero que rechaza incluso todo cuanto se ha escrito antes de él. La literatura nace cada vez con cada sujeto que escribe y en la voluntad de abolir todas las literaturas anteriores. Puede que el escritor imite a veces, pero será contra su voluntad e inconscientemente (Barthes y otros, I976).

El escritor resulta un tipo insólito -como se veía a sí mismo el nicaragüense Rubén Darío-, seducido por la palabra y sus poderes (Acedera Extremiana, 2005: 423444). Suele refugiarse en su mismidad, de donde saca materia prima para su libro en gestación. La obra conclusa es parte de él mismo, un fragmento de vida, un adminículo natural irremediable y rebelde; algo más, en suma, que un montón de cuartillas escritas en negro sobre blanco. El padre Coloma, cuya figura literaria se aborda luego en este artículo, sostenía que algo de Dios estaba en las palabras (Charques Gámez, 20I4: I8I-I94), y tal creencia repercutió marcadamente en su dicción literaria y en la estética general de sus libros (Behiels, I999: 59-66; Serna Galindo, 200I: 295-355).

Las obras de cualquier literato pretenden ser testigos de que él ha pasado por la existencia con determinado criterio. En definitiva, el autor quiere dejar señal de que ha ocupado un lugar y un tiempo concretos. El escritor, según el extinto académico y amigo epistolar Alonso Zamora Vicente, debe prepararse para creer en las cosas importantes porque su misión es la de inventar dando testimonio de sus verdades, que a la vez son también verdades o realidades de su tiempo histórico. Es aquí donde literatura e historia se entrecruzan en una primera instancia a través del nexo del autor literario (Merino,

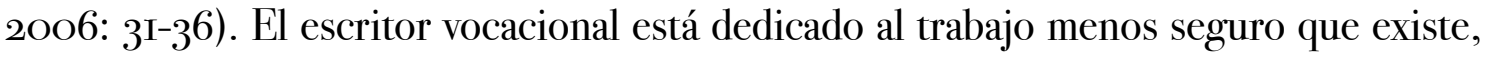
pues el arte no es sino una tentativa. Y la sociedad únicamente es capaz de remunerar las cosas tangibles, nunca los sueños ni las utopías (Zamora Vicente, 1958). 


\section{Novelas con historia. Una sucinta referencia a Pérez Galdós}

Mesonero Romanos se admiraba en sus memorias de que Galdós intuyese tan a fondo y con tino sin igual los tiempos de la época de Fernando VII sin haberlos visto ni vivido personalmente (Rubio Cremades, 2OOO: 2OI-2I2). Refiriéndose a Memorias de un cortesano de 1815, dice del libro que en él supo trazar el novelista un cuadro consumado de la Corte de aquella época, y añade:

no se sabe qué admirar más, si la misteriosa intuición del escritor, que por su edad no pudo conocerla, o la sagacidad y perspicacia con que, aprovechando cualquier conversación o indicaciones que hubo de escuchar de mis labios, ha acertado a crear una acción dramática con tipos verosímiles, casi históricos, y desenvolverla en situaciones interesantes, todo con un estilo lleno de amenidad y galanura (Mesonero Romanos, ı926; 2003).

Parte de la crítica suele anotar las posibles influencias de autores como Honoré de Balzac, Víctor Balaguer y Antonio Flores en la concepción de la serie novelística de los Episodios galdosianos. Nos parece de interés referenciar, aunque sea a vuela pluma, algunas de las ideas y desarrollos vertidos en el libro de Miralles titulado La segunda serie de los Episodios nacionales de Benito Pérez Galdós. De la historia a la novela. El libro aborda la segunda serie de los Episodios partiendo de una perspectiva poco habitual. Se enfoca a partir de la interdependencia entre el sustrato puramente histórico y el estrato de la fabulación. El autor se fija en los límites entre la historia y la creación literaria, y a la vista de la documentación procedente de una historiografía cercana al novelista canario, bucea por las márgenes histórica e imaginativa, estudiando de qué manera magistral se combinan en las novelas de la segunda serie de los Episodios ambos componentes, dando como resultado final un retrato impagable de la España del reinado de Fernando VII (Miralles García, 20I5).

Galdós fue un hombre discreto, poco aficionado a relatar intimidades personales, ni siquiera a mezclar el quehacer literario con su vida cotidiana. El caso de Galdós resulta significativo en este sentido, ya que es difícil dar con la auténtica persona detrás del personaje público. Se conoce que él se sentía poco atractivo para su público lector. Así se lo da a entender a Clarín cuando este le pide datos personales para un estudio. Incluso opina que entre el escritor y el lector conviene poner «una pequeña muralla de la China, honesta y respetuosa», y añade a continuación: «las confianzas con el público me revientan. No me puedo convencer de que le importe a nadie que yo prefiera la sopa de arroz a la de fideos» (Trapiello, 2or6: 7). El canario era bien celoso de su vida privada. Aparte de modas y momentos, también cuentan los modos y formas de ser en esto de ofrecer intimidades en los ámbitos de la vida creativa. 


\section{La novela, un género fuente para el historiador}

La novela es un elemento narrativo principal que acepta la elongación, extensión y aun deformación de sus estructuras básicas elementales. Dentro de las hechuras más aceptadas de la misma, caben mil experimentos, unos que se han llevado a cabo y otros renovados que habrán de llegar, además de un ciento de recursos de estilo que apoyan la confección de la obra y que en sí mismos terminan confundidos en su compleja urdimbre. El historiador se ha de valer de cualquier medio para conocer, para investigar, para dar luz al objeto de rastreo, y en la novela es posible hallar materia prima de deducción histórica (Serna Alonso, 2003: 227-264; Merino, 2OI4: 5-II).

Es en la narrativa justamente, y sobre todo en la novela, donde hallamos ejemplos de cómo este género literario puede convertirse a veces en fuente donde abocarse el historiador sediento (Canal Morell, 20I5: I3-23). La Real Academia Española fija la definición de fuente diciendo que se trata de un «material que sirve de información a un investigador o de inspiración a un autor». Como hemos visto, Galdós es el caso de creador literario más descollante en lo que hace referencia al uso de material sensible para convertirse en fuente histórica si hablamos de España, país en el que, por cierto, la novela por entregas jugó un papel fundamental en el ámbito de la prensa de la segunda mitad del siglo XIX (Fuster García, 2OII: 55-72; Gómez-Tabanera García, 2OII: I6I-I79).

Parece lícito preguntarse por qué razón es bueno leer novelas para confeccionar el relato de la historia (Serna Alonso y Pons, 2OOI: 94-IO2; Rodríguez Fischer, I998: 2I22). La respuesta es sencilla. En primer lugar porque las novelas nos aproximan a los seres humanos de nuestro mismo pasado, y eso hace que el historiador esté más preparado y dispuesto para contar historias acaecidas a determinados individuos, en vez de contar la historia en abstracto, que siempre interesa menos. Al final se comprende que el ser humano, en su individualidad, es el verdadero actor y artífice de la historia. En las novelas se halla, según el novelista Vargas Llosa, el reflejo de la subjetividad de una época (Vargas Llosa, 20O2). La subjetividad es ciertamente la clave del valor de la novela como fuente histórica, porque es capaz de «reflejar aspectos de la realidad omitidos por esas otras fuentes más objetivas» (Fuster García, 20II: 55-72). Especialistas en historia política y social han abogado por la utilización de una metodología histórica en la que los textos de memorias, epistolarios y novelas pudiesen tenerse en cuenta como fuentes documentales a la hora de investigar el pasado. La novela acerca a los nombres propios de ayer, los humaniza y los hace razonables para el ciudadano maduro. Por ejemplo, Unamuno nos hace comprender de cerca a los liberales y carlistas de Bilbao en Paz en la guerra (1897). Está claro que la novela no desvela el dato histórico preciso - para eso están los documentos-, pero sí nos da la ocasión de contemplar la historia desde otra perspectiva valiosa. Tuñón de Lara escribe que «para el historiador es algo tan importante [la obra literaria] como un archivo de Estado o un protocolo notarial» (Tuñón de Lara, 1993: 404). 
También es positivo leer novelas porque desempeñan un papel en el devenir de la historia, son parte de la misma y se encuentran en las coordenadas de los productos literarios, por lo que se estudian y clasifican en la historia del acontecer literario.

Sin embargo, según escribió la londinense Woolf en r932, la lectura de la novela no es labor simple, pues «no sólo requiere gran sutileza perceptiva, sino también extraordinaria audacia imaginativa si queremos aprovechar todo lo que el novelista -el gran artista- nos ofrece» (Woolf, 20I2: 29). Ficción e historia suelen compartir una finísima frontera del todo permeable porque la historia no deja de tener una buena parte de relato, y la novela viene a conformar otra manera de leer la historia (Jablonka, 20I4; Canal Morell, 20I5: 13-23).

Los profesionales de la historia deberían leer novelas, y leerlas con atención, para mejorar sus maneras expresivas a la hora de contar la historia. Los científicos sociales, en términos generales, no suelen escribir bien aun siendo reputados profesionales de su campo con larga experiencia a sus espaldas (Becker, 2OII: I9 y IOO). El buen historiador ha de ser también un prosista digno; de ese modo transmitirá mejor la historia investigada y llegará a un público lector más amplio (Marquard, 2OI2: 23; Savater Martín, 2OI3: 9-I4). Por lo general, cuando se trata de historiadores de lo económico, político o social los que echan mano de la novela como fuente, no son bien vistos por ciertos colegas, e incluso se sienten obligados a justificar el uso de este tipo de fuentes por considerarlas ajenas a su ámbito tradicional de documentación. Pero es evidente que la novela aporta un valor añadido en cualquier esfera de la investigación histórica. Avilés defiende esa utilización como un plus de calidad que el historiador puede aportar al margen del área o especialidad en la que se mueva.

Pero, ¿tiene sentido leer novelas para aprender historia? En mi opinión la respuesta es afirmativa. No tanto en el caso de las novelas históricas, cuya documentación se basa en estudios históricos anteriores, por lo que difícilmente podrían ofrecer información que no se hallara en éstos. Sí en el caso de las novelas que se basan en las experiencias propias del autor y de sus contemporáneos (Avilés Farré, I996: 337-360).

La historiografía actual mantiene dos paradigmas o modelos de investigación histórica: la tradicional y la científica. La primera obedece a la lógica de la narración ordenada y sucesiva; la segunda es la que, centrada en estructuras, recurre al estudio de los hechos seriados y al análisis abstracto. Ambas líneas tienden actualmente a completarse y confluir. Como señala Morales, explicación y comprensión no tienen por qué ser excluyentes (Megill, I993: 7I-96; Morales Moya, I987: 35-36; 1993: 229-257; 1994: I3-32). Lo cierto es que hoy la noción narrativa gana puntos, y se tiende a que historiadores y sociólogos escriban y expliquen mejor sus textos en pro de una comprensión mayor de los receptores, que no han de ser necesariamente historiadores (Vattimo, 1990). La demanda de los propios lectores aficionados a la historia, está propiciando la vuelta a la narración como forma expresiva de los investigadores. 
En puridad, la novela es más que un género en el que caben extraños ecos e infinitas herramientas creativas. Echando la vista atrás, vemos que la novela actual es fruto evolucionado de la novela de la segunda mitad del siglo XIX y primer cuarto del XX (Rodríguez Marín, I982; López Romero, 200I). En ese caldo de cultivo tuvo su nacedero contemporáneo, su campo de experimentación y su progresivo asentamiento (Shaw, I976: I73-260).

Los escritores siempre han buscado definir y delimitar el género de la novela. Parece una obsesión, una necesidad de concretar el camino para recorrerlo luego con mayores garantías de arribar a buen puerto. El semiólogo y ensayista francés Roland Barthes apunta la idea de que la novela es una gran frase dividida en secuencias. Magnífica definición por lo que tiene de generalista, aunque incompleta. O poco precisa, si se prefiere. Las definiciones del género llegan a no importar. Lo que cuenta de verdad es la forma literaria, el alma del relato. Y de manera especial, el lenguaje y la intencionalidad de los autores (Barthes, 2002).

La novela es un género en constante cambio. Los grandes novelistas lo han visto de modo parecido; algunos como Blasco Ibáñez, Galdós, Unamuno, Baroja, Pemán, Sender, Pessoa, Aldecoa, Cela, Delibes y tantos otros grandes mitos de nuestras letras peninsulares, han tenido una idea muy concreta, a veces intuitiva y generacional, del asunto, y han hallado herramientas ajustadas a su tarea personal como literatos y testigos de su tiempo (Levergeois, 2007: IO9-III). La novela se convierte a veces en informadora del momento político, en ficción capaz de sobrepasar sus propios límites naturales (LyonCaen, 20I5: 65-82). Esto es lo que interesa destacar: la novela como género es dúctil, capaz de adaptarse para que el autor sea, a su través, testigo de su espacio y su momento (Fuster García, 2OII: 55-72). Lo vemos de una manera clara en España a partir, sobre todo, de la evolución socio-cultural de la primera mitad del siglo XIX. La raíz de semejante progreso habría que buscarla sin duda en el cambio que supusieron a todas luces las Cortes de Cádiz y la consecuente Constitución, aprobada el i9 de marzo de i8I2. Estos acontecimientos no quedaron limitados al campo político, sino que obviamente compelieron cambios sociales, culturales y hasta literarios. Supuso el desmantelamiento del Antiguo Régimen y se liberalizó el comercio y la industria, con las consecuencias que la historia refleja y todos conocemos en relación al cambio de mentalidad y a la recepción de nuevos tiempos, formas y actitudes (Matés Barco, 20I2: 59-75). De ahí que el historiador pueda beber del manantial importante que supone el testimonio literario, puesto que en ocasiones la literatura no deja de ser un reflejo fiel de los hechos acaecidos (Morales Moya, 1994: 13-32).

El novelista refleja en sus obras -lo pretenda o no, y con mayor o menor lucidez e intensidad según los casos- el estado de cosas en derredor en un determinado periodo temporal. Los escritores están condenados a relatar lo que conocen, y nada como vivir para tener experiencia relatora. El novelista puede llegar a ser notario de su tiempo (Almela Boix, 2006: 97-I42). En algunos autores lo vemos con mayor claridad, como en Flores o en Galdós, que nos ofrecen historia viva a través del código escrito (Ortiz Armengol, 
2000; Sánchez García, 2007). Pero lo apreciamos igualmente en Unamuno, Ignacio Aldecoa y en todos los novelistas que han sido o son alguien en el ámbito de las letras españolas y extranjeras. Dado que la historia podría ser comparada a un denso arbusto repleto de ramaje e historias conexas, es interesante que el profesional de la historia esté atento a lo que la literatura puede aportar a ese complejo entramado (Canal Morell, 2OI4).

Estudiando la novelística del siglo XIX, observamos que los escritores del realismo viven, igual que lo hicieron Marx o Engels, en contextos de ascenso de la clase burguesa, y este aspecto también se refleja con meridiana claridad en sus escritos. El investigador de la historia puede sacar numerosos elementos de interpretación de los contenidos de la prosa decimonónica. Los escritores del movimiento realista mantienen que la realidad es la materia novelable donde los escritores se mueven como testigos de su tiempo histórico, y de ahí su manera de enfocar la novela como un relato fidedigno de la vida tal cual es o tal y como la han conocido o percibido en sus carnes.

Hay que ponderar el valor documental que encierran para los historiadores todas las artes, y muy en especial la literatura, que es testimonio y reflejo de la vida y expresión palpable de una mentalidad -la del escritor- enfrentada a su propio medio. Además, si la literatura puede mantener el rol de fuente histórica, la historia sirve a su vez a la literatura a la hora de encuadrar los contextos en los que surgen y se desarrollan las obras creativas (Seco Serrano, I988). Es evidente que la narratividad vuelve como una manera de hacer y escribir la historia.

Los personajes son actores esenciales en el devenir de un relato, sea breve o no. En la novela histórica, por ejemplo, las buenas etopeyas vienen a reforzar notablemente la mera descripción de los hechos narrados (Jurado Morales, 2006). Algunos escritores del realismo decimonónico tuvieron una especial sensibilidad en la composición de las etopeyas femeninas de calidad, como fue el caso de Leopoldo Alas o del padre Coloma, quien además se manejó muy bien en el género de la novela histórica (González Mejía, 2003; Romero Casanova, 2OII; Serna Galindo, 20I3: I25-I4I).

Lo que hay de común en todas las novelas, sean del tipo que sean, es que son narraciones ficticias. La inventiva del escritor resulta esencial en la factura del género. Porque contar una historia real sin que medie de alguna forma la fantasía en el proceso equivaldría al ejercicio de la crónica, y eso es cosa bien distinta (Pont Ibáñez, I997).

La narrativa, y especialmente la novela, es un recipiente formidable en el que los escritores embuten sus historias, comparten vergüenzas e infunden vida a sus personajes fundamentales. La novela es vida y testimonio, y el historiador pretende, justamente, referir los hechos de la vida. Los textos literarios expresan en ciertas ocasiones más de lo que aparentan decir en su epidermis. Y en ese tapado exponer y redescubrir está el motivo fundamental de la utilidad de la literatura creativa para el investigador de la historia (Veyne, 1984).

Recordemos aquella célebre idea de Pío Baroja en relación con los valores de la novela. En La objetividad de la Historia, escribe: «Es más exacta la novela buena para reflejar el mundo social que el libro histórico excelente» (Saz Parkinson, 20II). La obra 
de este gran escritor, y en especial El árbol de la ciencia, aporta el testimonio para comprender en buena medida la llamada crisis finisecular española del siglo XIX. Las novelas que Pío Baroja publica entre I9OO y I920, son documentos que nos ayudan a profundizar en ese proceso y en sus particularidades (Fuster García, 2OII: 55-72).

El historiador, escribe Ranke, «no se propone más que describir las cosas tal como fueron» (Ápud Bloch, I975: II8), y eso mismo creyeron ya algunos historiadores clásicos de la antigüedad, en especial Heródoto. Esto es lo que hace exactamente la literatura de tinte o contexto histórico: describir la realidad tal y como ha sido, aunque otorgando a los textos un matiz imaginativo que viene a reforzar el mensaje y que se diluye luego en el laberinto de los argumentos (Fernández Rodríguez, 2005: IO3-I26; Jurado Morales, 2006).

\section{El caso de Luis Coloma en su novela Pequeñeces ( I890)}

Galdós es, con diferencia, el literato español más citado como fuente por los historiadores. Pero muchos escritores del siglo XIX encajarían igualmente en ese apartado especial de autores de cuya obra puede beber el historiador de nuestros días. Coloma nos parece uno de ellos, sobre todo en lo tocante al tema de la moral y la sociedad de su tiempo. Leyendo detenidamente sus relatos y obra mayor, observamos que es un defensor incondicional de la clase media, a la que conoce bien. Sin embargo, frecuenta más la aristocracia, que pinta con maestría en sus lienzos literarios. Baste citar títulos como Un milagro, La Gorriona, El primer baile, La maledicencia y Pequeñeces, entre otros escritos.

Pequeñeces ocupa un lugar significado. Surgió gracias a la insistencia que Pereda hizo a Coloma durante años para convencerlo de que escribiese una novela larga con argumentos de entidad. Una vez pergeñado el libro a grandes rasgos, Coloma pensó primero titular su novela La samaritana, aunque luego cambió de opinión y la intituló Pequeñeces. La línea principal del argumento la tenía bien meditada a fines de i887, pero en esas fechas todavía no lo había elaborado de la forma conveniente. La idea básica, sin embargo, ya era firme. Se documentó bien a través de las revistas de la época, especialmente en las crónicas de sociedad y noticias de sucesos, y lo hizo con mayor intensidad si cabe por medio de la revista La Ilustración Española y Americana, que sirvió en gran medida a sus propósitos. Pero si Luis Coloma no hubiera tenido acceso fácil a esta serie de datos, hubiese reflejado igualmente a la perfección los círculos aristocráticos que describe y critica en su novela, pues se movió con destreza en ellos largo tiempo.

Nos ofrece un lienzo de gran valor para analizar la época que le tocó vivir. En Pequeñeces conviven varios argumentos en paralelo. En uno de ellos, la intriga se desvela ligada al personaje de Jacobo Téllez, marido separado de la marquesa de Sabadell y amante de Curra Albornoz. Pero además, desde un punto de vista meramente literario, hay que consignar el hecho importante de que el jesuita consigue poner en pie un gru- 
po imperecedero de personajes a los que manejará luego con maestría. De esta manera, obtiene una entrega de acción dinámica y gran efectividad narratológica. Una novela que describe el ambiente y el clima histórico de la segunda mitad del siglo XIX, y muy particularmente de la etapa del Sexenio, años que refleja con brillantez. Esta novela, a la que algunos críticos clasificaron en su día como relato en clave (Fernández Rodríguez, 2005: IO3-I26), tan disímil de las que construye Galdós en sus Episodios Nacionales, tiene sin embargo en común con ellas la utilización de personajes que hacen de hilo conductor de tramas y planteamientos. El realismo que muestra Pequeñeces puede ser útil también a la mirada del historiador (Merino, 2006: 3I-36; Canal Morell, 20I5: I3-23).

Jacobo es un personaje esencial en los argumentos. Se trata de un libertino que va a tener importancia capital en el desarrollo del libro. Se podría definir el rol de Jacobo Téllez-Ponce como la bisagra de articulación entre la línea central de los argumentos de salón que protagoniza Curra y los argumentos de misterio, que discurren en paralelo y que él sustenta.

Pequeñeces se vendió de manera formidable. Según los datos más fiables, en I89I se expidieron en librerías cincuenta mil ejemplares de la obra. La polémica que acompañó la recepción del libro ejerció una notable propaganda que benefició la popularidad del escritor. Según cifras de Pardo Bazán, «la tercera edición de Pequeñeces (siete mil ejemplares), se vendió antes de terminarse, ni siquiera llegó a verse en librerías; desapareció de ellas por arte de birlibirloque» (Pardo Bazán, I89I-I893; 2004).

De esta obra se han hecho un sinfín de ediciones. Una de las últimas en español de las que se tiene referencia es la de José Belmonte Serrano (Belmonte Serrano, 2005). Otra edición que en su día favoreció la difusión de la novela de Coloma fue la que hizo Espasa-Calpe en 196r dentro de su mítica colección Austral. En este milenio, aparte de la citada de Belmonte Serrano, es reseñable la más reciente de Antonio Morales Moya, disponible en formato tradicional de papel y en versión electrónica (Morales Moya, 20I4: I-XXXVI).

Pequeñeces conserva un atractivo del que carecen otras novelas de la misma época. En algunos sentidos, es un apéndice de La Montálvez de Pereda. En iogi se publicó La espuma, de Armando Palacio Valdés, otra obra que fue considerada como un nuevo desafío crítico a la sociedad madrileña más relevante. Y unos años después, siguiendo la misma estela, se publicaron Gente conocida (I896) y La comida de las fieras (I898), dos de las primeras creaciones de Benavente Martínez.

A Pequeñeces se la ha tachado de sermón jesuítico, pero la obra no se encuentra en esas hechuras ni mucho menos, si bien es verdad que Coloma critica en el libro la corrupción de la alta sociedad madrileña, tolerante con aparentes pequeñeces que no lo son tanto. La aparición de este libro coincidió con un momento de resurgimiento de la influencia religiosa en España, considerada de buen tono en la Regencia, y proporcionó el insólito espectáculo de un clérigo escribiendo con unas formas cuasi naturalistas.

Tras un análisis argumental, parecen claros los paralelismos entre determinados episodios de la novela y algunos hechos de vida del escritor. Los paralelismos responden 
a una técnica literaria de ocultamiento que trata de enmascarar la biografía del escritor en el interior de la novela, otorgando a ciertos sucesos reales la calidad de imaginados.

Si bien Pequeñeces escasea de una depurada calidad estilística que se delata en las dosis de doctrina enfoscada que contiene, posee a cambio un atractivo que le aporta su justificación. Una obra narrativa digna de la mejor pluma de finales del siglo XIX. Es entretenida, contiene una buena carga de misterio y la ejecución funcional del argumento es impecable. Presenta personajes inolvidables, incluyendo esplendentes etopeyas, y no está exenta de una acertada ambientación que deja al descubierto buena parte del siglo XIX, por lo que es recomendable su lectura a historiadores e investigadores de dicho periodo. 


\section{Referencias bibliográficas}

- Abellán, J. L. (I97I). La cultura en España. Madrid: Edicusa.

- Acedera Extremiana, A. (2005). Dos caras desconocidas de Rubén Darío: el poeta masón y el poeta inédito. Hispania, 88, 423-444.

- Almela Boix, M. (2006). La novela histórica española durante el siglo XIX. En J. Jurado Morales (Coord.), Reflexiones sobre la novela histórica (pp. 97-I42). Cádiz: Servicio de Publicaciones Universidad de Cádiz.

- Avilés Farré, J. (I996). La novela como fuente para la historia. El caso de Crimen y castigo (I866), Espacio, Tiempo y Forma, V, 337-36o.

- Baroja y Nessi, P. (1982). Memorias, t. V, La intuición y el estilo. Madrid: Caro Raggio.

- Barthes, R. (2002). Variaciones sobre la literatura. Barcelona: Paidós Comunicación i36.

- Barthes, R. (1976). Escribir ¿por qué?, ¿para qué? En R. Barthes y otros (Coords.), ¿A dónde va la literatura? Caracas: Monte Ávila Editores.

- Becker, H. (2OII). Manual de escritura para cientificos sociales. Cómo empezar y terminar una tesis, un libro o un artículo. Buenos Aires: Siglo XXI.

- Behiels, L. (1999). La estética de contrastes del P. Luis Coloma en Pequeñeces. En M. Steenmeijer y L. Behiels (Edits.). Asimilaciones y rechazos. Presencias del Romanticismo en el realismo español del siglo XIX. (pp. 59-66). Amsterdam/Atlanta: Rodopi, Serie Foro Hispánico, 5.

- Belmonte Serrano, J. (2005). Introducción. En L. Coloma Roldán, Pequeñeces (pp. 7-35). Madrid: Mare Nostrum, Col. Clásicos, I8.

- Blanco Rodríguez, J. A. (i996). La actitud de Martí ante los españoles y la presencia de éstos en el Ejército Libertador cubano. En J. P. Fusi y A. Niño (Eds.), Antes del desastre: Orígenes y antecedentes de la crisis delg8 (pp. 2II-223). Madrid: Universidad Complutense.

- Bloch, M. (1975). Introducción a la historia. México D. F.: Fondo de Cultura Económica.

- Canal Morell, J. (20I4). La historia es un árbol de historias. Historiografía, política, literatura. Zaragoza: PUZ, Prensas Universitarias.

- Canal Morell, J. (20I5). El historiador y las novelas. Ayer 97, I3-23. 
- Charques Gámez, R. (2OI4). El escritor misionero. Ideología y creación literaria en el padre Coloma. En J. Urrutia Gómez y D. Thion Soriano-Mollá(Eds.). De esclavo a servidor. Literatura y sociedad (I825-I930) (pp. I8I-I94). Madrid: Biblioteca Nueva.

- Coloma Roldán, L. (I89i). Pequeñeces. Bilbao: Administración de El Mensajero del Corazón de Jesús; (1961), Buenos Aires: Espasa Calpe, Col. Austral nº 413; (1987), edición de Rubén Benítez. Madrid: Cátedra, 5 ed.; (2005), edición de José Belmonte Serrano. Madrid: Mare Nostrum; (2OI4), edición de Antonio Morales Moya. Madrid: Ediciones I9.

- Díaz Freire, J. J. (20I5). Miguel de Unamuno y Bilbao. La experiencia melancólica de la modernidad. Ayer 98, 2I-44.

- Díaz-Plaja, G. (I969). Eloficio de escribir. Madrid: Alianza.

- Fernández Rodríguez, P. (2OOI). La literatura del siglo XIX y los orígenes del contubernio judeo-masónico-comunista». En I. Hassán y R. Izquierdo (Coords.), Judíos en la literatura española (pp. 3OI-352). Cuenca: Ediciones de la Universidad de Castilla-La Mancha.

- Fernández Rodríguez, P. (2005). La novela de clave en la Restauración o la literatura en pos de la verdad histórica. Studi Ispanici I, IO3-I26.

- Fucini, L. (2005). Calvino e la logia del barone Rampante. En 1805-2005. Due secoli dalla Constituzione del Supremo Consiglio d'tralia del Rito Scozzese Antico Accettato (pp. 227-233). Roma: Gran Loggia d'Italia.

- Fuster García, F. (2OII). La novela como fuente para la Historia Contemporánea. Elárbol de la ciencia de Pío Baroja y la crisis de fin de siglo en España. Espacio, Tiempo y Forma, V, 23, $55^{-72}$.

- Gómez de la Serna, R. (I970). Nuevas páginas de mi vida. Madrid: Alianza.

- Gómez-Tabanera García, J. M. (2OII). La llamada novela por entregas y su caracterización en la España del siglo XIX. En E. Rubio Cremades, M. Sotelo Vázquez y otras (Coords.), La literatura española del siglo XIX y las literaturas europeas (pp. I6I-I79). V Encuentro de la Sociedad de Literatura Española del siglo XIX: PPU, Promociones y Publicaciones Universitarias.

- González Martín, F. J. (i996). La crítica contubernista, mito y antropología en el pensamiento barojiano (І9II-I936). En J. A. Ferrer Benimeli (Coord.), La Masonería en la España del siglo $X X$ (pp. 789-8I4). Actas VII Symposium Internacional de Historia de la Masonería Española [Toledo, abril I995]. Toledo: Universidad de Castilla-La Mancha, Cortes de Castilla-La Mancha y CEHME. 
- González Mejía, M. (2003). Los personajes femeninos en la novela española del siglo XIX. Tesis doctoral. Madrid: UNED, Universidad Nacional de Educación a Distancia.

- Jablonka, I. (2OI4). L'histoire est une littérature contemporaine. Manifeste pour les sciences sociales. París: Seuil.

- Jurado Morales, J. (2006). Reflexiones sobre la novela histórica. Cádiz: Servicio de Publicaciones de la Universidad.

- Lejeune, P. (1994). El pacto autobiográfico y otros estudios. Madrid: Megazul-Endymion

- Levergeois, B. (2007). Pessoa. Défenseur des Frères. Humanisme 278, IO9-III.

- López Romero, J. (200I). La novela del siglo XIX en Jerez de la Frontera. Jerez: Servicio de Publicaciones del Ayuntamiento.

- Lyon-Caen, J. (2015). Escribir el tiempo político. Una ficción de i848. Ayer 97, pp. 65-82.

- Mainer Baqué, J. C. (I998). Reconstruir la España contemporánea (entre la literatura y la historia). Ayer 3I, 83-98.

- Mainer Baqué, J. C. (20I5). La historia de la literatura como historia (para una defensa e ilustración del pirronismo literario). Ayer 97, 37-64.

- Marquard, O. (20I2). Individuo y división de poderes. Estudios filosóficos. Madrid: Trotta.

- Matés Barco, J. M. (2012). Los parlamentarios americanos y la Constitución de ior2. En M. A. Chamorro y J. Lozano (Eds.). Sobre un hito jurídico. La Constitución de 1812. Reflexiones actuales, estados de la cuestión, debates historiográficos (pp. 59-75). Jaén: Universidad de Jaén.

- Megill, A. (1993). Relatando el pasado. Descripción, explicación y narrativa en la historiografía. Historia Social ı6, 7 I-96.

- Merino, J. M. (2006). Historia y literatura. En J. Jurado Morales (coord), Reflexiones sobre la novela histórica (pp. 31-36). Cádiz: Servicio de Publicaciones de la Universidad.

- Merino, J. M. (20I4). Novela e historia. Peonza Io9, MEC, Ministerio de Educación y Cultura, $5^{- \text {II. }}$

- Mesonero Romanos, R. de (1926). Memorias de un setentón, natural y vecino de Madrid. Madrid: Renacimiento; (2003), Alicante: Biblioteca Virtual Miguel de Cervantes.

- Miralles García, E. (20I5). La segunda serie de los Episodios nacionales de Benito Pérez Galdós. De la historia a la novela. Vigo: Academia del Hispanismo. 
- Moradiellos García, E. (2004). La persistencia del pasado. Escritos sobre la historia. Cáceres: Servicio de Publicaciones de la Universidad de Extremadura.

- Morales Moya, A. (1987). Algunas consideraciones sobre la situación actual de los estudios históricos. La(s) otra(s) historia(s), I, nº I, junio, UNED de Bergara (Guipúzcoa), 35-36.

- Morales Moya, A. (1993). Biografía y narración en la historiografía actual. En Problemas actuales de la historia (pp. 229-257). Salamanca: Universidad.

- Morales Moya, A. (i994). Formas narrativas e historiografía española. Ayer ı4, I3-32.

- Morales Moya, A. (20I4). Estudio introductorio. Nobleza y sociedad liberal: la obra del P. Coloma. En L. Coloma Roldán, Pequeñeces (pp. I-XXXVI). Madrid: Ediciones I9.

- Ortiz Armengol, P. (2000). Vida de Galdós. Barcelona: Crítica.

- Pardo Bazán, E. (I89I-I893). Nuevo Teatro Crítico. Madrid: La España Editorial; (2004), Alicante: Biblioteca Virtual Miguel de Cervantes.

- Pérez Galdós, B. (20I6). Correspondencia. Edición de Alan E. Smith, M. A. Rodríguez Sánchez y Laurie Lomash. Madrid: Cátedra.

- Pont Ibáñez, J. (ed) (1997). Narrativa fantástica en el siglo XIX (España e Hispanoamérica). Lérida: Milenio.

- Renan, J. E. (1972). La reforma intelectualy moral. Barcelona: Edicions 62.

- Rodríguez Fischer, A. (1998). Por quéleemos novelas. Barcelona: Ariel.

- Rodríguez Marín, R. (I982). La novela en el siglo XIX. Madrid: Playlor.

- Romero Casanova, C. P. (2OII). La novela histórica de Luis Coloma. Trayectoria y actualización biográfica y crítica. Tesis doctoral, Universidad de Alicante.

- Rubio Cremades, E. (2000). Visión y análisis de la prensa en Memorias de un setentón, de Ramón Mesonero Romanos. Anales de Literatura Española, I4, 2OI-2I2.

- Salinas Serrano, P. (i97o). Los poderes del escritor. En P. Salinas, La responsabilidad del escritor (p. 2I7). Barcelona: Seix Barral.

- Sánchez Gálvez, S. (2007). Martí ciñó el mandil. Prueba documental de su filiación masónica. La Habana: Casa de Altos Estudios don Fernando Ortiz. 
- Sánchez García, R. (2007). Galdós ante el Sexenio democrático. Cuadernos de Historia Contemporánea, Extra 2, 28I-29O.

- Savater Martín, F. (2013). Figuraciones mías. Sobre el gozo de leer y el riesgo de pensar. Barcelona: Ariel.

- Saz Parkinson, C. R. (2OII). Positivamente negativo. Pío Baroja, ensayista. Madrid: Servicio de Publicaciones de la Universidad Complutense.

- Seco Serrano, C. (i988). Criterios historiográficos, Diario I6, 26-XI.

- Serna Alonso, J. (2003). El pasado que no cesa. Historia, novela y agnición. Ayer 5I, 227264 .

- Serna Alonso, J. y Pons, A. (2OOI). Los viajes de Carlo Ginzburg. Entrevista a Carlo Ginzburg. Archipiélago 47, 94-IO2.

- Serna Galindo, R. (200I). Estética literaria de Pequeñeces, novela del Padre Coloma. Un preclaro antecedente de la narrativa conservadora del siglo XX. Cuadernos de Aragón 27, 295-3I5.

- Serna Galindo, R. (20I3). El padre Coloma y su novela Pequeñeces. Noticia breve acerca de algunos personajes. Costa Rica, REHMLAC, Revista de Estudios Históricos de la Masonería Latinoamericana y Caribeña, diciembre 20I3-abril 2OI4, I25-I4I.

- Shaw, D. L. (1976), Historia de la literatura española. Elsiglo XIX. Edición al cuidado de José Carlos Mainer. Barcelona: Ariel.

- Trapiello, A. [Andrés García Trapiello] (20I6). Suyo afectísimo, Benito Pérez Galdós, Babelia, Suplemento Cultural, El País, I6-VII-20I6, p. 7 .

- Tuñón de Lara, M. (i993). Literatura e historia. Discurso de investidura como Doctor honoris causa por la Universidad de Baleares [octubre, 1984]. En J. L. de la Granjay A. Reig (Eds.). Manuel Tuñón de Lara: el compromiso con la historia. Su vida y su obra (p. 404). Bilbao: Universidad del País Vasco.

- Vargas Llosa, M. (2002). La verdad de las mentiras. Ensayos sobre la novela moderna. Madrid: Alfaguara.

- Vattimo, G. (I990). La sociedad transparente. Barcelona: Instituto de Ciencias de la Educación de la Universidad Autónoma y Paidós.

- Veyne, P. (1984). Cómo se escribe la historia. Foucault revoluciona la historia. Madrid: Alianza. 
- Vila Vilar, E. (2009). Historia y Literatura: un largo debate para un caso práctico. Nuevo Mundo Mundos Nuevos, 3I-VI.

- White, H. (1992). Metahistoria. La imaginación histórica en la Europa del siglo XIX. México: FCE, Fondo de Cultura Económica.

- White, H. (2003). El texto histórico como artefacto literario. Barcelona: Paidós.

- Woolf, V. (2012). ¿Cómo debería leerse un libro? Barcelona: José J. de Olañeta.

- Zamora Vicente, A. (1958). Voz de la letra. Madrid: Col. Austral, ı287, Espasa-Calpe. 